\title{
Docentes resilientes em contextos precários: estudo de casos em Espanha
}

\author{
Resilient teachers in precarious contexts: case studies in Spain
}

\author{
Carolina Silva Sousa* \\ Universidade do Algarve \\ Marta Olmo Extremera** \\ Universidade do Algarve
}

Resumo $\mathrm{O}$ artigo centra-se sobre docentes que enfrentam grandes desafios, em contextos socioeconómicos e culturais muito precários, na Província de Granada, Espanha, em que os alunos apresentam muitas diferenças quanto às suas necessidades e aspirações educativas. Os docentes destas escolas acabam por atuar numa perspetiva mais social e moral do que académica e as famílias demonstram pouca participação e interesse, junto às instituições de ensino nas quais os seus filhos estudam. As respostas obtidas com a recolha de dados são únicos para cada contexto social e educacional e seria errado extrapola-las, a partir de um centro para outro, porque cada centro tem a sua própria realidade, apesar do elevado envolvimento dos docentes para o sucesso das suas escolas.

PALAVRAS-ChAVE: Docente resiliente; Resiliência; Fatores de resiliência.

Abstract The article focuses on teachers who face major challenges in very poor socioeconomic and cultural contexts in the Province of Granada, Spain, in which students present many differences in their needs and educational aspirations. The teacher of these schools end up acting in a more social and moral perspetive than academic and the families show little participation and interest among the educational institutions where their children study. The answers obtained from the data collection are unique to each social and educational context and it would be wrong to extrapolate them from one center to another, because each center has its own reality. Despite the high involvement of teachers for the success of their schools.

KEYWORDS: Resilient teacher; Resilience; Factors of resilience. 


\section{Introdução}

Sendo inquestionável a ideia de que estamos a atravessar uma época que se tem vindo a revestir progressivamente pela imprevisibilidade, dinamismo, incerteza, interrogamo-nos, frequentemente, como implementar nas escolas uma convivência justa numa sociedade global, multicomplexa, plural e cada vez mais multicultural. Em que medida as guerras, as economias deficitárias, as desigualdades sociais, as políticas coercivas, a exclusão social não desagregarão as relações entre as pessoas, as relações entre as famílias e até que ponto tal não terá implicações na educação nas nossas escolas? Até que ponto os nossos docentes nas escolas investigam sobre o papel da autorrealização, assertividade, criatividade, cooperação, liderança, gestão da sua agenda pessoal e não implementam resiliência académica com os seus alunos, com base nas relações interpessoais, na sua empatia, habilidades sociais e sentimento de pertença a um grupo, na interface, por um lado, com a resiliência social e, por outro lado, com a resiliência emocional? Até que ponto, esses docentes não refletem sobre as experiências positivas desenvolvidas em situação de sala de aula, e que certamente podem bem contribuir para o desenvolvimento de sentimentos de autoeficácia, autoestima e sucesso académico, concorrendo para o desenvolvimento das suas habilidades, bem como a transmissão e aquisição de valores individuais e sociais, tendo em vista um bem maior que é o da educação?

Estamos bem conscientes das dificuldades inerentes ao ato educativo na formação de quaisquer profissionais, particularmente, quando as áreas de formação são caracterizadas por uma pluridimensionalidade antropológica, cultural, ética e axiológica, que tornam o processo de elaboração de um corpo teórico específico e a sua partilha como uma estratégia simultaneamente complexa e sedutora (Sousa, 2010). Efetivamente, se o fim da educação - básica, média ou superior, deve ser o desenvolvimento humano, ter-se-á que pugnar por uma sociedade e por um ensino, cujo grande objetivo será o de formar profissionais competentes, não no sentido em que serão apenas aptos para esta ou aquela tarefa, mas aptos em termos gerais, isto é, capazes de lidar eficazmente com toda a realidade circundante, por mais difícil, desafiadora e complexa que esta se apresente.

\section{Docentes resilientes}

Um docente resiliente deverá pontuar em focar a sua energia essencialmente nas oportunidades que a situação educativa lhe oferece, clarificando valores, redefinindo prioridades, em que se apresenta como imprescindível uma ação de flexibilidade, com tolerância à ambiguidade e à incerteza, sem perda do equilíbrio emocional e intelectual, em que situações imprevistas e inesperadas proporcionam simultaneamente riscos e oportunidades. Para um docente resiliente é importante a abertura à criatividade e à inovação, capacidade de adaptação rápida e permanente à mudança, perceção das oportunidades, atitude positiva perante a vida, aceitação das diferenças, legitimação da tomada de decisão por consenso, diálogo com os seus alunos, perseverança, paixão pela sua tarefa educativa e preservação dos valores, entre outros aspetos. Um docente resiliente enfrenta os desafios do quotidiano, lutando pela consistência dos seus princípios e valores, enfrentando as situações com flexibilidade, humor, empatia, afeto, responsabilidade, otimismo, paixão, sentido de humor, ou seja, a capacidade para rir de si mesmo e das situações (Gottlieb, 1999). 
$\mathrm{E}$, do nosso ponto de vista, um docente resiliente, pode muito contribuir para implementar resiliência com os seus alunos, nas suas escolas. E uma questão, neste momento, gostaríamos de colocar: Que fatores afinal poderão contribuir para o delineamento de um perfil de docente resiliente?

Estudos realizados por autores como Uriarte (2006) referem que as qualidades pessoais mais importantes que facilitam a resiliência para um professor são autoestima consistente, convivência positiva, assertividade, altruísmo, flexibilidade de pensamento, criatividade, autocontrolo emocional, independência, autoconfiança, autoestima e sentimento de autoeficácia, otimismo, locus de controlo interno, iniciativa, senso de humor e moral. O mesmo estudo, enfoca a importância deste docente ser capaz de se comprometer com um projeto educacional, ser emocionalmente estável, possuir alta motivação, ser tolerante à frustração, de espírito corajoso e apaixonado pelo que faz.

É interessante estarmos conscientes que as realidades das escolas localizadas em áreas socioeconômicas desfavorecidas é cada vez maior e tal é preocupante. Estamos a falar de centros educativos, que exigem uma capacidade de resiliência grande bem como alto compromisso de seus professores. Ao mesmo tempo, em espaços como estes, os professores são expostos a altos níveis de exaustão e stress emocional, podendo tal gerar desânimo e pessimismo sobre o desempenho de seus alunos. E, então, colocam-se as seguintes questões: Como deve ser uma escola que eduque para a resiliência? Um docente pode desenvolver a resiliência nos seus alunos? E quais as características de uma personalidade resiliente?

Do nosso ponto de vista, e relativamente à primeira pergunta, uma escola que pretenda educar para a resiliência será uma escola que deve empenhar-se em aumentar e promover nos seus alunos laços pro sociais, definindo limites claros e consistentes, proporcionando apoio e atenção afetivo-relacional, ensinando habilidades de vida, manifestando e estabelecendo altas expectativas, proporcionando apoio adequado e oportunidades para que estes possam ter uma participação efetiva na vida escolar, estabelecendo redes com os pais e membros da família dos alunos, ou seus substitutos, visando a construção de um sentido de comunidade dentro da escola. De realçar que a combinação das altas expectativas e o apoio adequado proporcionará aos alunos uma melhor autoeficácia, autoestima, otimismo, autorrealização, autogestão e pensamento crítico. Sobre a questão: Um docente pode desenvolver a resiliência nos seus alunos? A tarefa educativa de um docente caracteriza-se por imprevisibilidade, complexidade, gestão de situações de caráter multifacetado e assente em realidades multidinâmicas, sendo por isso exigível que intervenha como ser humano, dotado de competência, maturidade, perseverança e resiliência, com capacidade de tomar decisões e operacionalizá-las, em circunstâncias, muitas vezes, adversas. Até porque um docente com mais condições de ser bem-sucedido é aquele que constrói e reconstrói uma vida saudável, impregnada de relações interpessoais elevadamente positivas na interação com os seus alunos e comunidade educativa. E na sua tarefa de potencialização de seres humanos resilientes, num ambiente em que uma percentagem significativa da população não usufrui daquela satisfação e daquele bem-estar que lhe é imprescindível para a sua árdua tarefa a de aprender e ensinar - e onde a ausência de paz, a injustiça social, o desrespeito pelos 
direitos humanos e a falta de igualdade, entre outros, constituíram nos últimos tempos os novos fatores determinantes para o bem-estar docente, tal conduz-nos à reflexão de quão importante é para um docente implicar-se na formação e na educação de seres humanos íntegros e preparados para enfrentar a imprevisibilidade da sociedade que temos e em que vivemos. E sobre a questão: $E$ quais as características de uma personalidade resiliente? Como todos sabemos, a personalidade do ser humano pode já conter as ferramentas da resiliência. A investigação aponta para que a resiliência é o resultado de características particulares associadas ao comportamento sociável, temperamento, caráter e inteligência (Grotberg, 1995). De facto, um crescente número de estudos internacionais, transculturais e de caráter longitudinal (Werner e Smith, 1982) têm vindo a validar pesquisas anteriores que postulam que todo o ser humano nasce com uma capacidade inata de resiliência, através da qual pode desenvolver a sua capacidade de adaptação. É esta capacidade que lhe possibilita, mesmo em presença de graves riscos, ser capaz de superar as desvantagens e transformar uma trajetória de risco/ de vulnerabilidade em resiliência, apresentando-se como um ser humano competente, confiante, empático, com humor e atencioso. Efetivamente, os traços da personalidade resiliente pressupõem a existência de uma comportamento que pretende ser construtivo, adaptativo e socialmente estável, na medida em que os indivíduos resilientes se caracterizam por apresentarem um conjunto de competências que lhes permitem lidar de forma mais eficaz com as situações stressantes, tais como competências sociais, de metacognição, autonomia e capacidade de planeamento do seu futuro.

Todavia, é de salientar que no entender de Freitas e Downey (1998) não existe um perfil considerado específico dos indivíduos resilientes, mas sim características comuns a indivíduos com personalidade resiliente, características estas que se começam a verificar na infância e que permanecem presentes no percurso de vida dos indivíduos, em que a principal característica é o facto de apresentarem uma personalidade particularmente capacitante para confronto com o stresse crónico ou com adversidades quotidianas. Todos conhecemos histórias de resiliência com relatos de trajetórias de vida de alguns jovens que venceram. Mas o que dizer daqueles adolescentes em que surgem casos de suicídio e depressões, consumo de drogas e outras substâncias ilícitas, anorexias, e ou bulimias, alienação, delinquência e outros comportamentos inadaptativos? Afinal que constrangimentos ocorreram na trajetória desenvolvimental destes jovens adolescentes? E o que pode um docente, um docente resiliente, fazer para interagir e apoiar estes adolescentes? Mas o professor também se confronta com envolvimentos físicos pobres e desorganizados, falta de serviços de apoio, adolescentes em risco, problemas comportamentais, emocionais, violência e maus tratos, insucesso académico, abuso de substâncias, entre outros. De facto, muitas situações profissionais com que o professor se confronta são de uma dificuldade muito elevada, em que pontuam pela sua relevância um conjunto de estratégias de ordem atitudinal, social e emocional que acabam por contribuir para o ajudar na construção de uma adaptação positiva frente ao contexto. 


\section{Metodologia}

Trata-se de um estudo de caso desenvolvido a partir de uma abordagem qualitativa e de uma perspetiva exploratória descritiva (Stake, 1995). Entendemos ser esta metodologia a mais adequada para compreendermos em profundidade a realidade educativa e social, assim como os fatores de resiliência postos em prática por parte dos professores das distintas instituições de ensino estudadas na Província de Granada, Espanha.

Os casos estudados foram selecionados intencionalmente junto a escolas, cujas gestões e medidas de atuação levadas a cabo pelas equipas gestoras, estivessem marcadas por grandes desafios.

O desenho metodológico - estudo de caso apresenta como objetivo a compreensão da particularidade dos casos que se investigam, com a intenção de saber como funcionam as partes que o compõem, relacionando-as entre si e tendo como fim a formação de um todo. Através da análise dos dados identificamos diferenças significativas quanto ao uso de fatores de resiliência. Importante destacar que as escolas estudadas estão situadas em contextos socioeconómicos e culturais muito precários, em que os alunos apresentam muitas diferenças quanto às suas necessidades e aspirações educativas. Os professores acabam por atuar numa perspetiva mais social e moral do que acadêmica e as famílias demonstram pouca participação e interesse junto às instituições de ensino nas quais os seus filhos estudam.

\section{Participantes}

Os participantes do estudo, num total de 17 docentes, nos quais foram identificados variedades e diferenças quanto ao número de anos de lecionação, à sua experiência profissional, às formas de trabalhar com os alunos, aos modos de relacionar-se, desenvolver-se e comprometer-se com o contexto, com a cultura e com o trabalho pedagógico. Estes aspetos influenciam no funcionamento das escolas pesquisadas pois há grupos de professores que acabam por não se adaptar ao contexto educativo no qual estão inseridos. Trata-se de instituições de ensino instaladas em ambientes precários e isto produz certa resistência de adaptação para os professores. Há segmentos de ensino em que os docentes têm que adaptar os conteúdos das suas disciplinas a níveis muito básicos o que pode contribuir para sérias frustrações no seu desenvolvimento profissional. Neste sentido, a empatia do professor com o tipo de escola na qual leciona torna-se essencial, caso pretenda chegar a obter bons resultados, tanto académicos, como de funcionalidade das escolas.

No entanto, a percentagem de docentes cujo grau de compromisso contribui para o melhoramento escolar e social dos seus alunos é elevada, pois estes implicam-se e persistem no apoio e no trabalho em equipa, ante as dificuldades com as quais se confrontam e lutam com paixão por aquilo em que acreditam, tentando fazer das suas escolas um lugar de êxito. 


\section{Instrumentos}

Os instrumentos de recolha de dados utilizados são próprios das investigações de caráter etnográfico, com imersão na realidade. Neste sentido, fizemos uso de entrevistas em profundidade.

As entrevistas em profundidade permitiram-nos compreender, de uma forma exaustiva, o conhecimento, a perceção e o contexto dos entrevistados. O diálogo entre iguais, produzido nas entrevistas, possibilitou debater detalhadamente sobre a variável resiliência. Gerou, também, um bom clima afetivo relacional e uma atmosfera interessante e agradável, onde os sujeitos participantes podiam expressar-se de uma forma livre, fazendo emergir a sua teoria prática em contraste com a teoria formal dos investigadores, conseguindo uma teoria fundamentada sobre o processo de desenvolvimento da escola e da sua função como docente.

Os dados obtidos através deste instrumento têm sido interpretados, por um lado, a partir da análise do discurso, identificando os componentes principais (objeto do estudo) e por outro, identificando os elementos que envolvem o discurso (contexto e formas de atuação), tornando compreensível o seu conteúdo e respetivos efeitos.

Focamos a análise do discurso a partir de um ponto de vista linguístico, o que significa analisarmos a língua por detrás das orações, focalizando sobre estas de uma forma minuciosa, buscando muito mais do que palavras bem ordenadas nas frases. Neste caso, analisamos a forma como a variável resiliência é entendida por parte dos docentes das escolas estudadas.

\section{Análises de dados}

Os dados obtidos nas análises foram extraídos através do programa estatístico qualitativo Nvivo. Realizamos uma análise da variável resiliência para conhecermos de forma mais detalhada o conteúdo que a definia, assim como o significado de seus fatores de maior percentagem e como estes têm sido usados por parte dos sujeitos participantes, derivando em elementos que nos auxiliam a identificar que fatores têm sido mais e menos usados pelos participantes, atendendo às características próprias de cada instituição escolar. Por último, a análise de dados cruzados com a resiliência, sendo usada como variável principal, permite conhecer como esta é interpretada por parte dos docentes; inventariar que fatores de resiliência coincidem entre diferentes grupos de professores, assim como a relação de frequência e, por fim, saber quanto ao uso e o não uso destes fatores nas práticas docentes dos informantes e sua relação com as escolas em que lecionam.

\section{Resultados}

Os resultados deste estudo dão-nos a conhecer o significado da resiliência para os sujeitos participantes. Ao estudar esta variável e os seus fatores no corpo docente investigado, detetamos muitas disparidades nos resultados, entre uns e outros. Há fatores que são nulos em umas escolas enquanto que em outras são muito comuns e estão altamente presentes. 
Na Tabela 1 pode-se observar os fatores de resiliência mais usados por parte dos docentes de cada escola e que relação de percentagem há entre uns e outros, tendo em conta que esta relação está determinada pelas características e particularidades de cada instituição de ensino.

Tabela 1. Fatores de Resiliência e seu uso por parte do professorado

\begin{tabular}{|l|l|l|l|}
\hline $\begin{array}{l}\text { Fatores de } \\
\text { Resiliência }\end{array}$ & Professores Escola A & Professores Escola B & Professores Escola C \\
\hline Resiliência & $44,33 \%$ & $12,02 \%$ & $43,66 \%$ \\
\hline Apoio & $33,16 \%$ & $41,20 \%$ & $25,64 \%$ \\
\hline Compromisso Social & $79,63 \%$ & $2,34 \%$ & $18,23 \%$ \\
\hline Constância & $18,31 \%$ & $30,29 \%$ & $51,40 \%$ \\
\hline Criatividade & $0 \%$ & $91,91 \%$ & $8,08 \%$ \\
\hline Diálogo & $11,76 \%$ & $88,23 \%$ & $0 \%$ \\
\hline Empatia & $31,87 \%$ & $1,91 \%$ & $66,22 \%$ \\
\hline Esperança & $31,22 \%$ & $0 \%$ & $68,77 \%$ \\
\hline Humor & $6,77 \%$ & $0 \%$ & $93,23 \%$ \\
\hline Melhora & $54,16 \%$ & $7,33 \%$ & $38,57 \%$ \\
\hline Oportunidade & $55,75 \%$ & $44,24 \%$ & $0 \%$ \\
\hline Paixão & $67,12 \%$ & $6,44 \%$ & $26,44 \%$ \\
\hline Positividade & $39,07 \%$ & $0 \%$ & $60,93 \%$ \\
\hline Reflexão & $32,37 \%$ & $1,63 \%$ & $66,01 \%$ \\
\hline & & & \\
\hline
\end{tabular}

Como se pode constatar, o uso da resiliência apresenta uma percentagem similar entre a Escola A $(44,33 \%)$ e a Escola B (43,66\%). Enquanto, com uma menor percentagem (12,02\%), encontramos os professores da Escola B. A sua conceção a respeito da resiliência, apesar de guardar uma estreita relação com as características das demais escolas, apresenta similitudes entre os docentes das escolas, já que a resiliência é interpretada como: a capacidade de adaptar-se ao contexto, relacionando-se com este, buscando laços de apoio entre uns e outros, com a finalidade de superar as adversidades, a partir de uma visão positiva que busca bons resultados e um funcionamento ótimo de uma organização escolar. Consequentemente, pode -se inferir, que a resiliência e a sua interpretação estariam sendo usadas e concebidas de igual maneira nas escolas com características equivalentes, como podemos ver em ambas as escolas, a partir da perspetiva dos seus docentes. Contudo, aquelas escolas cujas características são distintas, a resiliência apresenta outras conotações quanto à sua interpretação. Como é o caso da Escola B, donde se considera a resiliência como um elemento que caracteriza uma instituição escolar em seu funcionamento, organização e gestão de lideranças.

No que se refere aos fatores da resiliência e ao seu uso pelos docentes, cabe destacar as percentagens com similitudes. Como mencionado anteriormente, há que sublinhar que há fatores que apresentam mais diferenças. Isto poderia indiciar que, apesar das escolas estudadas terem características similares, no que se refere a aspetos de caráter socioeconómico, cultural, alunos e rendimento acadêmico, no uso dos fatores de resiliência, há grandes diferenças entre uns e outros docentes. 


\section{Fatores de Resiliência Comuns entre os Docentes}

Dos fatores de resiliência comuns entre os participantes da pesquisa são de destacar quatro: oportunidade, apoio, constância e melhoria.

O fator oportunidade está representado por uma percentagem de 44,24\% $\mathrm{DEB}^{1}$ frente a uma percentagem de $55,75 \% \mathrm{DEA}^{2}$. Tal é interpretado como a capacidade de levar a cabo novas formas de trabalhar na escola, com novas dinâmicas de aprendizagem e didática em aula, assim como outorgar mais autonomia para criar intervenções e iniciativas por parte dos professores.

Não obstante, os $\mathrm{DEC}^{3}$ não fazem alusão a este fator. Este facto chamounos a atenção depois de conhecermos a história desta escola. As suas razões poderiam estar relacionadas com a exiguidade do tempo que tem a nova equipa diretiva. Entre o discurso dos seus participantes, identificam-se outros fatores próprios da resiliência, para além de situações (disputas e rivalidades entre os membros da equipa diretiva) que têm gerado um clima institucional com conotações negativas e com baixa esperança em mudar e melhorar.

Por outro lado, o fator melhora, é composto pelas seguintes percentagens, designadamente: $51,16 \%$ (DEA), 7,33\% (DEB) e 38,57\% (DEC). Frente a esta variável, os docentes das Escolas A e C apresentam percentagens próximas. Contudo, os DEB apresentam uma percentagem da ordem de 7,33\%. Estes dados prendem-se diretamente com os resultados e o funcionamento acadêmico de cada escola. Tanto os DEA como os DEC apresentam resultados próximos já que necessitam melhorar os seus aspetos acadêmicos e organizativos. Neste sentido, é marcante a diferença dos DEB em cujos discursos não está muito presente esta variável devido ao bom funcionamento, resultados e organização escolar.

Outro fator, o fator perseverança, está representado pelas percentagens de $18,31 \%$ (DEA), 30,29\% (DEB) e 51,40\% (DEC). Embora as percentagens não sejam muito próximas entre uns e outros é de especial interesse destacar este fator devido ao facto de que é muito citado nos distintos discursos dos sujeitos participantes. Os professores das três escolas consideram que a perseverança é imprescindível para conseguir aquilo que a escola persegue, que é necessária para combater as adversidades que surgem.

Por último, se encontra o fator apoio representado pelas percentagens de $33,16 \%$ (DEA), 41,20\% (DEB) e 25,64\% (DEC) respetivamente. Esta variável é relevante no caso das três escolas estudadas por parte dos seus professores.

Apesar de identificarmos coincidências de fatores de resiliência entre os grupos de professores das três escolas estudadas, as diferenças entre os fatores são mais significativas. Portanto, consideramos interessante destacar aqueles fatores cujas diferenças são maiores. 


\section{Discussão e considerações finais}

O artigo debruçou-se sobre a problemática da resiliência, concretamente tomou como objeto o docente resiliente em contextos socioeconómicos culturais precários.

Os resultados deste estudo revelam que o uso de fatores de resiliência pelos professores participantes apresentam uma correlação direta com as características dos centros a que os mesmos pertencem, apresentando como fatores mais comuns: oportunidade, melhoria, perseverança, apoio, diálogo, empatia, esperança, humor, paixão, extraídos através das vozes dos sujeitos, refletidas na análise dos seus discursos. $\mathrm{O}$ domínio destes fatores, não permite a generalização dos resultados, uma vez que se trata de um estudo descritivo, mediante o recurso a uma metodologia de natureza de estudo de caso.

No entanto, convém enfatizar, neste momento, que cada centro educativo tem suas as peculiaridades que o tornam único.

Por outro lado, o facto de o professor estar neste centro surge mais como um dever e não como uma necessidade, revelando perfeita consciência de que integram um centro com quem assumem um compromisso, mais de ordem social e moral que de ordem académica. A este propósito recordamos os estudos levados a cabo por Acevedo e Restrepo (2011) sobre os professores que trabalham com alunos que apresentam dificuldades acadêmicas em que tomando a variável resiliência, defendem que se deve reforçar o processo de ensino-aprendizagem, o que aqui não ocorreu.

Este estudo indicia, ainda, que o domínio da engenharia da resiliência pode ajudar os alunos a melhorar as suas dificuldades, quer a nível social quer a nível emocional.

Como se pode constatar, cada estudo determinou alguns fatores de resiliência inerentes, mas pensando no conjunto dos dados obtidos, são fatores que se complementam dado que a resiliência é um processo composto por um conjunto de fatores que interatuam entre si, incluindo a finalidade de obter um propósito individual ou coletivo. A este propósito, Block e Block (1990) referem-se aos indivíduos resilientes como seres humanos bem adaptados e com elevadas capacidades de natureza interpessoal, pois na sua ótica existe um permanente confronto entre o ego do indivíduo, quer entre a sua vertente mais resiliente, quer entre a sua vertente mais frágil e vulnerável, o que pode dificultar de forma significativa a sua capacidade de resposta às exigências resultantes das diferentes situações de vida stressantes e negativas.

Em definitivo, a resiliência e os seus fatores respondem a um uso específico e concreto partindo da realidade em que se encontra. Isto quer dizer que se trata de um conceito composto por fatores cujos resultados e impactos não se pode generalizar já que o que é eficiente para o desenvolvimento de uma escola pode não ser para outra. Portanto, poderíamos considerar de especial relevância a colocação em prática dos fatores de resiliência imersos nos processos em que docentes resilientes buscam êxito em três sentidos: alunos, escola, comunidade educativa. 
E todos estamos interessados em que docentes resilientes contribuam para a formação integral do nosso aluno, seja da formação inicial ou pós graduada, com um claro compromisso social, ético e político e fundamentado no diálogo de saberes entre estudantes, professores e comunidade educativa em que o docente resiliente pode jogar um papel de ativação da resiliência em contexto de uma educação para a vida.

\section{Referências}

ACEVEDO, V. E.; RESTREPO, L. De professores, famílias y estudantes; fortalecimento de la resiliência en la ecsuela. Revista Latinoamericana de Ciencias Sociales, Niñez y Juventud, v. 10, n. 1, 2002, p. $301-319$.

BLOCK, J.; BLOCK, J. H. The role of ego control and ego resiliency in the organization of behavior. Em Couins, W. A. (Ed.), Development of cognition, affect, and social relations. Hillsdale, NJ: Erlbaum, 1990, p. 45- 64.

FREITAS, A.; DOWNEY, G. Resilience: A dynamic perspetive. International Journal of Behavioral Development, v. 22, n. 2, 1998, p. 263- 285.

GOTTLIEB, B. H. Social networks and social support in community mental health. Em Gottlieb, B. H (Ed.), Social networks and social support. Londres: Sage, 1999, p. 11 - 42.

GROTBERG, E. A guide to promoting resilience in children: strengthening the human spirit. The hague: Bernard Van Leer Foundation, 1995.

HERRENKOHL, E.; HERRENKOHL, R.; EGOLF, B. Resilient early school- age children from maltreating home: Outcomes in late adolescence. American Journal of Orthopsychiatry, v. 62, n. 2, 1994, p. 301- 312.

MIRANDA, A.; JARQUE, S.; TÁRRAGA, R. Escuela. Em Ezpeleta, L. (Ed.), Fatores de Riesgo en Psicopatología del desarrollo. Barcelona: Masson, 2005, p. 203 - 223.

STAKE, R. E. The art of case study research. Universidad do Michigan: Sage, 1995.

URIARTE, J. D. Construir la resiliência en la escuela. Revista de Psicodidática, v. 11, n. 1, 2006, p. 7- 23.

WERNER, E. E.; SMITH, R. S. Vulnerable but invincible: A study of resilient children. New York: McGraw-Hill, 1982.

Notas

\footnotetext{
${ }^{1}$ Docente Escola B.

${ }^{2}$ Docente Escola A.

${ }^{3}$ Docente Escola C.
} 
* Professora doutora da Universidade do Algarve, Faro, Portugal.

** Professora doutora da Universidade Estadual Paulista Júlio de Mesquita Filho, São Paulo, São Paulo, Brasil

\section{Correspondência}

Carolina Silva Sousa - Universidade do Algarve, Escola Superior de Educação e Comunicação. Campus da Penha, Penha, CEP: 8005135 - Faro, Portugal.

E-mail: csousa@ual.pt-moemrt@correo.ugr.es

Recebido em 25 de outubro de 2016

Aprovado em 04 de novembro de 2016 
